\title{
José EsteVe PARDO, La nueva relación entre Estado y sociedad, Marcial Pons, Madrid 2013.
}

\author{
doi: 10.18543/ed-64(1)-2016pp409-411
}

La crisis económica está siendo objeto de estudio prácticamente desde el mismo momento en que a los europeos nos estalló delante de la cara mientras los más despistados pensábamos allá por 2008 que era una cuestión puramente americana. Sin ánimo de ser muy preciso, podríamos decir que en esa amplia reflexión colectiva se ha producido una especialización entre los economistas, que analizan las causas y los juristas, que nos centramos en las consecuencias que para nuestro ordenamiento está teniendo la crisis (ay, ese uso diario de los Gobiernos españoles del decreto-ley). Sin embargo, José Esteve Pardo, catedrático de Derecho Administrativo de la Universidad de Barcelona, ha roto este esquema para intentar una aproximación al trasfondo de la crisis que él considera de todos los Estados europeos y no de uno u otro en concreto. Su tesis, ya adelantada en el título, consiste en considerar que se ha quebrado el equilibrio entre la sociedad y el Estado que se consiguió en el mundo occidental tras la Segunda Guerra Mundial y de este movimiento telúrico -o «falla» como lo llama el autor- derivarían los problemas económicos, las terribles cifras del paro, la corrupción rampante, etc.
Antes de llegar a esta tesis, el profesor Esteve Pardo expone la evolución de la relación entre la sociedad y el Estado en los últimos doscientos años que, como todos sabemos, se puede resumir en lenguaje telegráfico diciendo que en ese tiempo se han sucedido dos grandes modelos: durante el siglo XIX y primer tercio del XX el Estado liberal propugnó la separación entre el Estado (regido por la Constitución) y la sociedad civil (el Código civil y los contratos); modelo que posteriormente fue sustituido por el Estado social. Lejos de pretender una originalidad imposible, el autor nos narra con prosa ágil y brillante esta conocida evolución de la mano de los más reputados autores, empezando lógicamente por Adam Ferguson -inventor de la expresión sociedad civil-y el gran Adam Smith, que explicó la dinámica que el mercado crea en la sociedad partiendo de la idea -en palabras de Harold Laski- de que «el negociante es un benefactor público». Nos encontramos a continuación con Mercier de la Riviere y los fisiócratas franceses; Hegel y Otto Gierke (con su contraposición entre Genossenschaft y Herrschaft) en Alemania; Martínez de la Rosa y Donoso Cortés en España, etc. 
Además de los pensadores, no faltan en esa explicación los elementos sociológicos, muy especialmente en el surgimiento del Estado social en la Constitución de Weimar de 1919, una vía intermedia entre el radicalismo de izquierda (muy deslumbrado en aquella época por la revolución bolchevique, añado yo por mi cuenta) y el tradicional estado liberal que pretendía estabilizar la convulsa situación económica y social que en aquella época vivía Alemania y, en general, toda Europa. El Estado social, sustentado en la legitimidad de la soberanía popular, buscaba corregir los defectos estructurales de la sociedad, objetivo que se plasma en el ordenamiento jurídico de diversas formas, entre las que destacan dos: por un lado en el nacimiento de los derechos sociales (el derecho a la educación, a la protección a la salud, etc) y por otro en una nueva concepción de la propiedad, que de derecho absoluto pasa a tener una «función social». Claro que para lograr la materialización de estas ideas hace falta transformar el Estado abstencionista liberal y ampliar extraordinariamente el sector público, fortaleciendo la Administración del Estado (con el efecto secundario de entrada de la sociedad en el Estado por medio de la nueva burocracia), hasta el punto de transformar los municipios -tradicionalmente consideradas corporaciones sociales- en administraciones públicas.

Ahora bien, el objetivo de corregir los defectos estructurales de la sociedad, que se marca el Estado social, implica un crecimiento exponencial del sector público en todos sus frentes, desde el incremento del número de funcionarios hasta el aumento de la presión fiscal, lo que lleva al punto clave de este tipo de Estado: su sostenibilidad económica debida a su demanda continua de más fondos para ir cubriendo sus siempre crecientes costes. Por eso, algunos pensadores de la categoría de Max Weber y García Pelayo tenían la idea -ahora demostrada errónea- de que se produciría una total integración entre la sociedad y el Estado con predominio de éste. Sin embargo, en el último tercio del siglo XX se ha producido un reflujo y la sociedad no solo ha recobrado cierta capacidad autorreguladora, sino que incluso ha logrado que funciones que antes se consideraban propias del Estado sean realizadas por la sociedad, desde la gestión de muchos servicios públicos hasta el grueso de la investigación científica y técnica, sin olvidar importantes resortes económicos, tantos que incluso los Estados parecen quedar a merced de empresas tan opacas como las agencias de calificación. Y de la misma forma que el Estado social supuso una reorganización de los poderes públicos, el nuevo Estado -que llamaremos postsocial, aunque Esteve se cuida de darle un nombre especial- que se está configurando en la actualidad se adecua a la nueva relación estado sociedad con nuevas entidades que se conciben como una retirada del Estado en favor de la sociedad: se reordenan las tradicionales administraciones corporativas, se crean múltiples administraciones independientes (que en España ofrecen un triste balance, capturadas por los partidos políticos) e incluso la Administración de Justicia sufre una pérdida de su monopolio de impartir justi- 
cia que se advierte no solo en el ámbito civil (así la reforma del artículo 414 de la Ley de Enjuiciamiento Civil para que el juez invite a las partes a un acuerdo), sino incluso en el ámbito penal, permitiendo en acuerdo entre las partes en algunos casos. En última instancia hasta se cambian las constituciones para garantizar la sostenibilidad del propio Estado, como pasó con la reforma del artículo 135 de la Constitución española.

Como no está conforme con esta situación, el profesor Esteve propone un cambio, que no es el de una imposible vuelta al Estado social tradicional sino una transformación del papel del Estado en la nueva sociedad. Así, el Estado debería de replegarse para convertirse en un Estado "garante» de los derechos y «regulador» de la economía, algo que viene propugnando un sector de la academia alemana y en cierta forma han hecho sus instituciones, a diferencia de «la frívola irresponsabilidad de nuestra clase política», opinión con la que intuitivamente la mayoría de los lectores nos identificamos. Precisamente, partiendo de esa frase uno empieza a darle vueltas a los aspectos que echa en falta en el libro porque muchos males de la actual crisis española están en esa frívola actuación de la clase política, genialmente descrita por Antonio Muñoz Molina en Todo lo que era sólido y que se manifiesta en múltiples aspectos, que no trata Esteve, o a los que alude muy de pasada, como a la invasión de políticos en las Cajas de Ahorros (cuya desastrosa gestión han sabido trasmutar en «crisis bancaria»), la ocupación política de multitud de cargos técnicos, que hace que -por citar ejemplos concretos- la mayoría de los puertos estén presididos por políticos o que en muchas Administraciones el «carnet» sea un mérito preferente para ocupar jefaturas de servicios, las oscuras privatizaciones en favor de amigos y compañeros de pupitre, por no hablar de la contradicción entre esa continua dejación de funciones públicas en manos privadas y el aumento del número de empleados públicos, casi tres millones en 2013. En el nivel más global, se echa en falta la ausencia en las páginas del libro de una reflexión sobre las organizaciones supranacionales, sobre todo de la Unión Europea, para mí un invento cooperativo de los Estados europeos por seguir siendo Estados en un mundo que los supera, así como de los bancos centrales y su activo papel en el sistema financiero mundial. En fin, temas muy extensos que quizás el autor ha preferido orillar para tratar en un nuevo libro, que yo desde luego estoy deseando que publique con rapidez.

Agustín Ruiz Robledo Universidad de Granada 